\title{
Harmonic Reduction Analysis for Electric Arc Furnace using Passive Filters and DSTATCOM
}

\author{
Priyashree S, Vidya H A
}

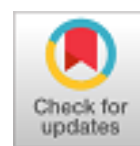

\begin{abstract}
The Industrial furnaces are used globally for wide range of applications from lab scale to complete production lines. They provide continuous high temperatures of $300^{\circ} \mathrm{C}$ to $3000^{\circ} \mathrm{C}$ with precise control of temperature and material flow to ensure consistent and uniform output. The furnace operators that deliver at higher efficiencies are prone to power supply system challenges with greater potential for power quality implications on supply system. Hence such operators of high intensity power furnaces should consider design and development of appropriate mitigation techniques to upgrade the power supply quality. In this paper the mitigation of harmonics in Electric Arc Furnace is dealt with suitable passive filter and DSTATCOM techniques. Also, the performance analysis of Electric Arc Furnace has been carried out with MATLAB/SIMULINK based model using Sinusoidal pulse width modulation, hysteresis and the sliding mode controllers.
\end{abstract}

Index Terms: Electric Arc Furnace, Hysteresis controller, Passive filters, Sliding mode controller and Total harmonic reduction.

\section{INTRODUCTION}

Electric Arc furnace (EAF) is one of the common loads in industry that introduce considerable distortion of current harmonics in distribution system. These unbalance load currents cause voltage fluctuations and voltage imbalance, affecting the operation of other electric equipments in the power system. Also there occurs initial decay of load current due to the existence of industrial furnaces in the distribution network. Hence appropriate actions are to be taken to reduce these power quality problems. Power quality analyzers (PQA) facilitate to identify power quality problems and assess the required compensation to reduce harmonics. Besides the energy storage systems and distributed generation, other devices used to solve PQ problems include dynamic voltage restorer, constant voltage transformer, isolation transformer, noise filters, static VAR compensators and harmonic filters (passive and active). With suitable interface or compensating devices, loads can be isolated from the disturbances that are originating from the grid. In the presence of passive filters the harmonic currents tend to flow along the impedance path. These filters are relatively

Revised Manuscript Received on October 30, 2019.

* Correspondence Author

Dr. Priyashree S*, Electrical \& Electronics Engineering, BNM Institute of Technology, Bengaluru, India.

Dr. Vidya H A, Electrical \& Electronics Engineering, Global Academy of Technology, Bengaluru, India.

(C) The Authors. Published by Blue Eyes Intelligence Engineering and Sciences Publication (BEIESP). This is an open access article under the CC BY-NC-ND license (http://creativecommons.org/licenses/by-nc-nd/4.0/) inexpensive compared to the other mitigating devices. Usually low pass, high pass, single tuned, double tuned and C-type high-pass filters are the conventional passive filters implemented to decrease the harmonic content in line current. The shunt active power filters (APF) are designed for the current harmonic compensation with voltage source inverter (VSI) connected to the main system. This VSI injects current to the system that is of the same magnitude as that of the load current but opposite in phasor. The main advantage of shunt APF is that the compensating current reference can be easily taken and force the converter to combine accordingly using VSI because of the presence of DC storage device For analysis of effective reduction in harmonics with passive filters and shunt compensators, an equivalent model of EAF is developed using MATLAB/SIMULINK. It also facilitates to obtain a better overview and operational behavior of EAF.

\section{MATHEMATICAL MODEL OF ELECTRIC ARC FURNACE}

Power quality analysis was carried out at M/s JSW Steel Plant, Bellary with an EAF load. The online readings of voltage, current, power, power factor and other significant electrical parameters were recorded using PQA. Data gathered at the EAF is shown in Table I, which is obtained using PQA at the supply side of EAF installation.

The voltage and current waveform on the supply side of EAF is shown in Fig. 1. The current THD of EAF is observed to be $\mathbf{3 5 . 4 4 \%}$ (as obtained using MATLAB program based Harmonic Analyzer for the data collected at the EAF steel plant) shown in Fig.2.

\begin{tabular}{|l|l|l|l|l|l|l|l|}
\hline $\begin{array}{l}\text { Thre } \\
\text { e } \\
\text { Phas } \\
\text { e } \\
\text { Supp } \\
\text { ly }\end{array}$ & $\begin{array}{l}\mathbf{V}_{\mathbf{s}} \\
\text { Volts }\end{array}$ & $\begin{array}{l}\mathbf{I}_{\mathbf{L}} \\
\text { Amps }\end{array}$ & $\begin{array}{l}\text { Real } \\
\text { Power } \\
\mathbf{( K W )}\end{array}$ & $\begin{array}{l}\text { Reactive } \\
\text { Power } \\
\mathbf{( K V A R )}\end{array}$ & $\begin{array}{l}\mathbf{V}_{\text {THD }} \\
\mathbf{( \% )}\end{array}$ & $\begin{array}{l}\mathbf{I}_{\text {THD }} \\
\mathbf{( \% )}\end{array}$ & $\begin{array}{l}\text { Power } \\
\text { Factor }\end{array}$ \\
\hline $\mathbf{R}$ & 1890 & 1362 & 0.0259 & 0.0226 & 1.46 & 9.31 & 0.7536 \\
\hline $\mathbf{Y}$ & $\begin{array}{l}9 \\
6\end{array}$ & 1070.25 & 0.0198 & 0.0191 & 2.34 & 12.18 & 0.7185 \\
\hline $\mathbf{B}$ & $\begin{array}{l}1830 \\
9\end{array}$ & 1281.25 & 0.0276 & 0.0148 & 2.00 & 10.27 & 0.8811 \\
\hline
\end{tabular}

In order to analyze the effective harmonic reduction, it necessitates use of common and precise model for EAF.

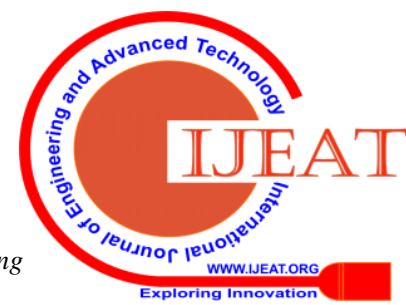


In this work, a three-phase time domain EAF model is developed using MATLAB/SIMULINK.

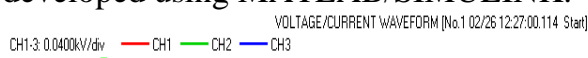

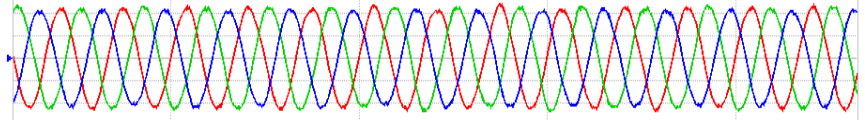

CH13 1.000 $/ \mathrm{d} \mathrm{dN}-\mathrm{CH} 1-\mathrm{CH}_{2}-\mathrm{CH}_{3}$

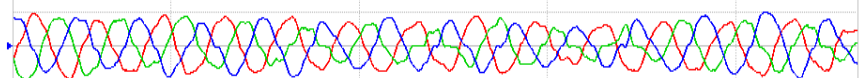

Fig.1 Current waveform on supply side of EAF
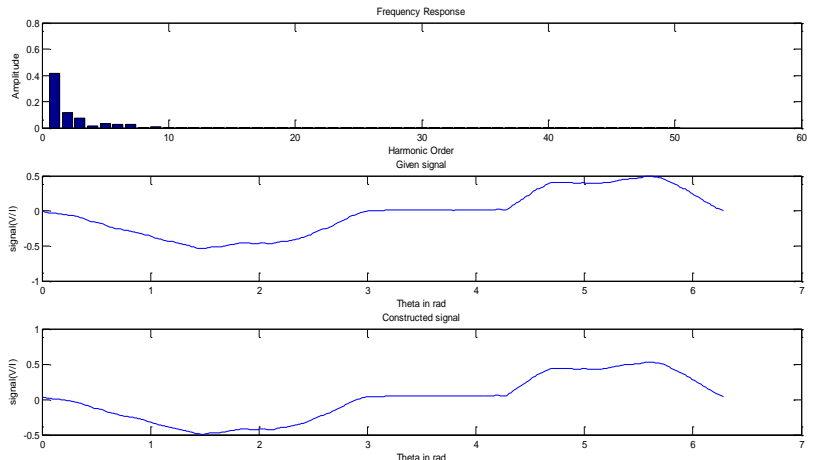

Fig.2 FFT Analysis of EAF Supply Current
The proposed model is designed based on the EAF at the installation with specified approximation. All the elements have been modeled using existing Simulink blocks that are available in the Simulink tool /Sim-Power-System blocks of MATLAB

Mathematical model of EAF is developed based on the classical Cassie and Mayr models that are applied extensively for the study of phenomena of an electric arc in the high-voltage circuit breakers. The suggested model of EAF pronounces the arc furnace as a device consisting of two-terminal corresponding to variables arc current and voltage, as shown in Fig. 3. This model employs the analysis of node voltages and obtain solution such that it can be appropriately realized using MATLAB/SIMULINK.

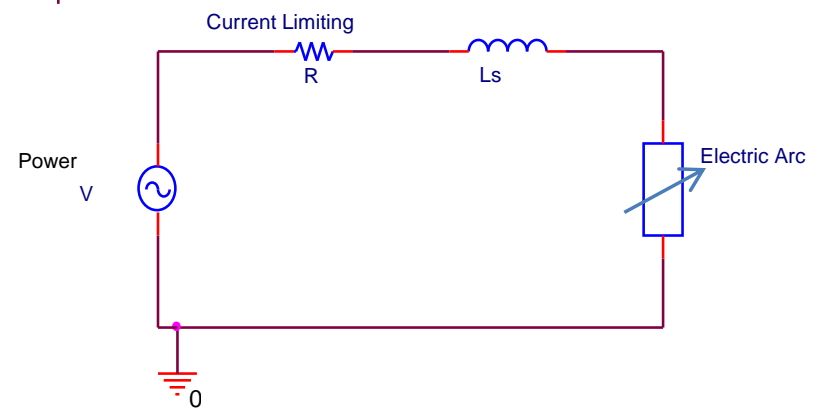

Fig3. Equivalent Circuit for EAF

Thus the general expression that indicates the conductance of EAF is represented by combining the Cassie and Mayr Models as given by Eq. (1).

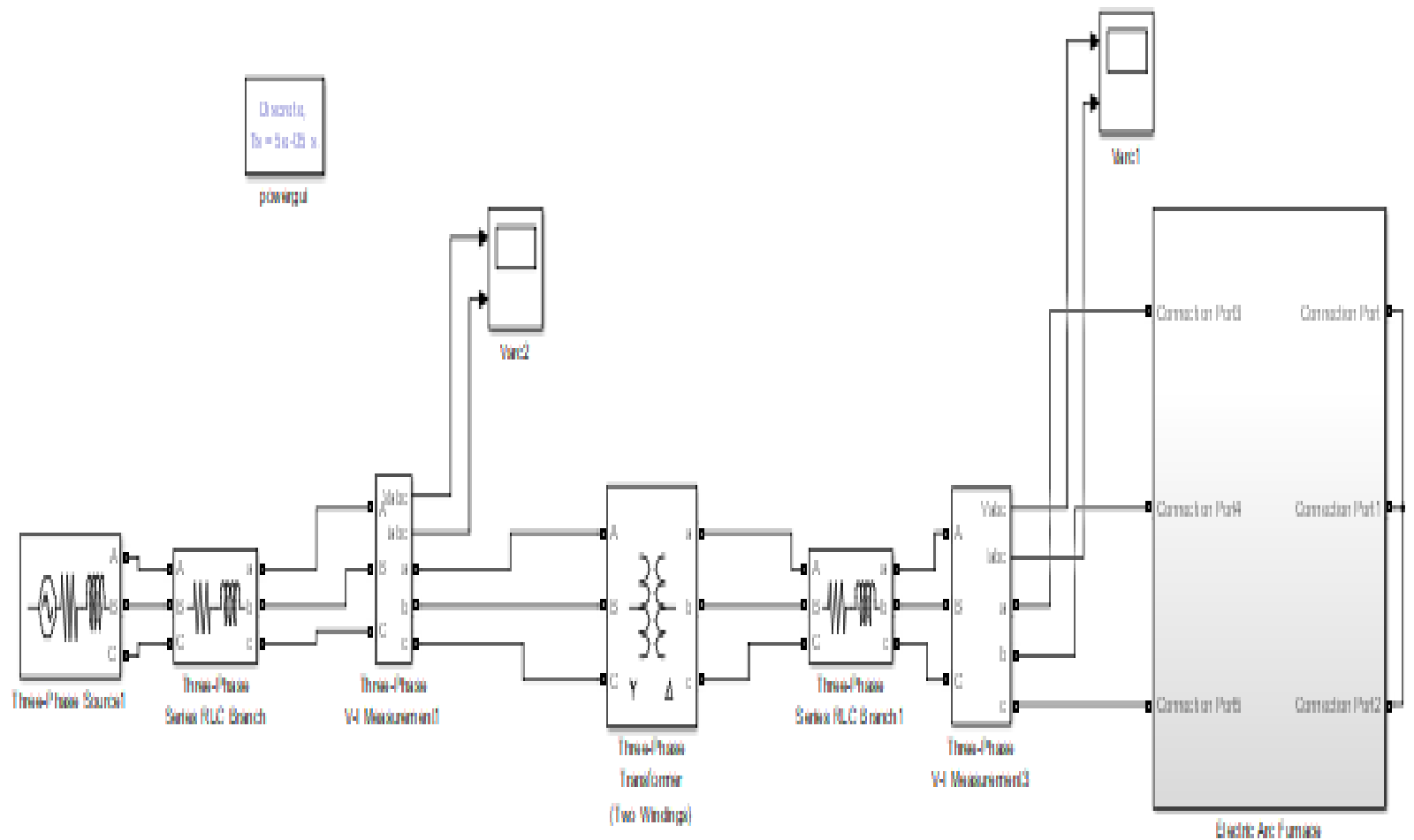

Fig. 4 Cassie - Mayr model of EAF using MATLAB/SIMULINK 


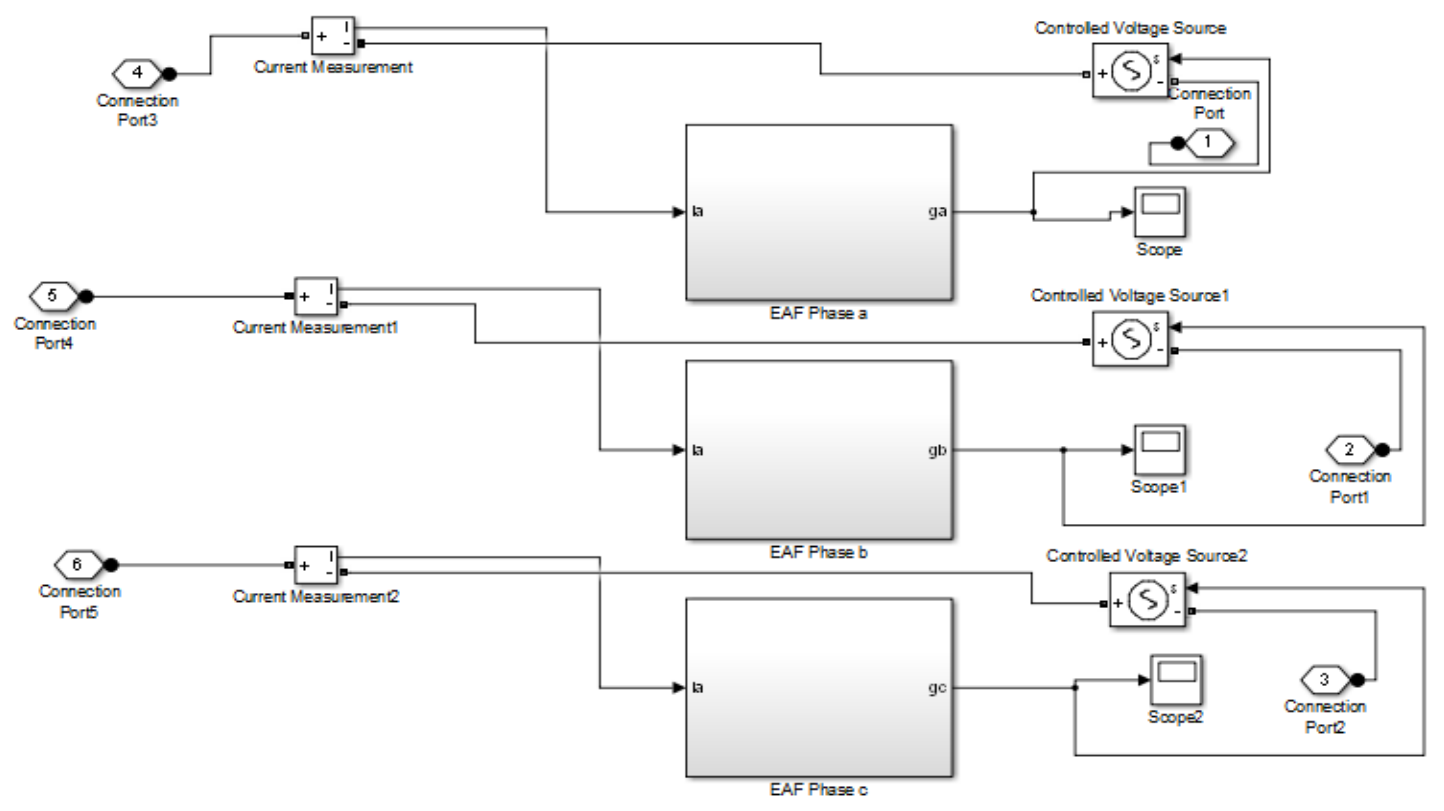

Fig. 5 Subsystem of EAF for Cassie - Mayr model

$$
g=g_{\min }+\left[1-e^{-\left(\frac{i^{2}}{V_{0}^{2}}\right)}\right] \frac{v i}{E_{0}^{2}}+\left[e^{-\left(\frac{i^{2}}{V_{0}^{2}}\right)}\right] \frac{i^{2}}{P_{0}}-\theta \frac{d G}{d t}
$$

From Eq. (1) the nine parameters: $\mathrm{g}_{\min }, \mathrm{i}, \mathrm{v}, \mathrm{I}_{\mathrm{o}}, \mathrm{P}_{\mathrm{o}}, \mathrm{E}_{\mathrm{o}}, \theta_{1}$, $\theta_{0}$ and $\alpha$ characterize the conductance of each phase for the proposed EAF model. The equivalent circuit of EAF using MATLAB is shown in Fig. 4. The subsystem of the selected model of EAF is shown in Fig 5.

The Supply Voltage and Current waveform on the supply side is shown in Fig. 6. The FFT analysis of EAF Cassie-Mayr model without filter is shown in Fig. 7. The supply current THD is obtained as $35.64 \%$.

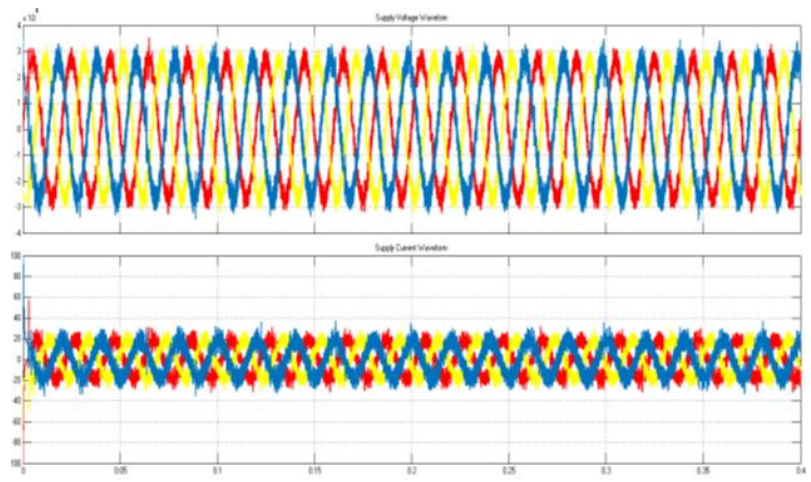

Fig.6 Supply Voltage \& Current of Cassie-Mayr model for EAF without filter

It is observed that the THD obtained from Cassie- Mayr model (35.64\%) is approximately same as THD obtained at the EAF steel plant (35.44\%). Hence, the harmonic reduction analysis of EAF is carried out using Cassie- Mayr model.

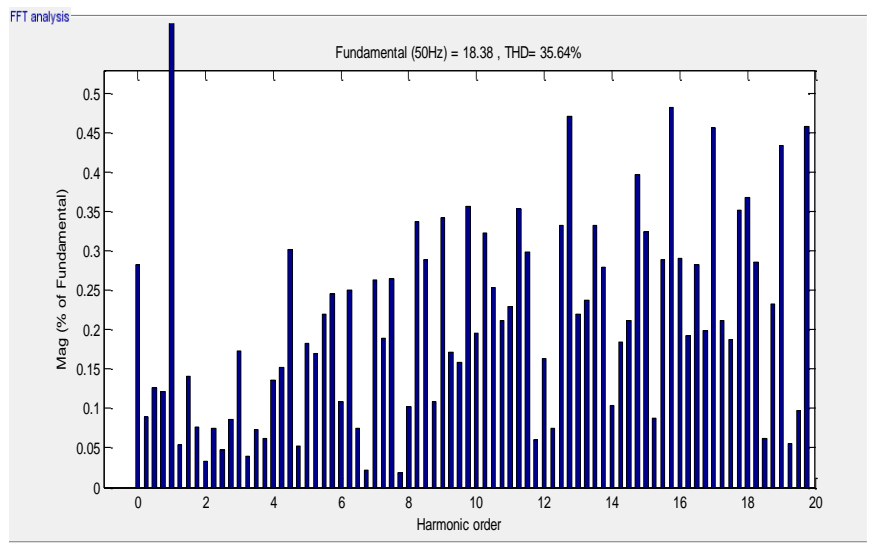

Fig.7 FFT Analysis of Cassie-Mayr model for EAF without filter

\section{HARMONIC REDUCTION ANALYSIS FOR EAF USING PASSIVE FILTER}

\section{A. About Passive Filters}

The filters that are composed of $\mathrm{R}, \mathrm{L}$ and $\mathrm{C}$ components are referred to as passive filters. They are simple filters without any active elements such as transistors or operational amplifiers. They are the representative of simplest application for a given system function as the number of necessary components are lesser.

Also, as they do not consist of active elements, supply of power is not mandatory. These passive filters operate better at large frequencies, since they do not possess bandwidth limitations such as that of operational amplifiers.

The passive filters are classified as series, shunt and their combination. Usually shunt passive filters are more preferable than series due to lower installation cost and better reactive power compensation capability.

\section{B. MATLAB/SIMULINK Equivalent Model of EAF with Passive Filters}

Analysis was carried out with the Passive filter based Cassie - Mayr model of EAF to observe reduction of harmonics in source current.

Blue Eyes Intelligence Engineering \& Sciences Publication

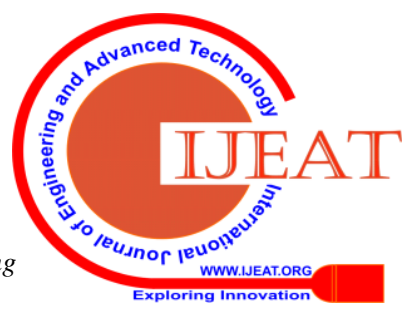


The simulations were carried out for different passive filters such as LC, High pass, Double tuned and C-Type High Pass. The Low Pass filter was connected on the supply side of the Cassie - Mayr model of EAF as shown in Fig. 8. The waveform of supply current with reduced harmonics for the Cassie-Mayr model of EAF with LC Filter is shown in Fig. 9. The FFT analysis of supply current for EAF with LC filter is as shown in Fig. 10. The THD of supply current was found to be reduced from $35.64 \%$ (without filter) to $5.58 \%$ (with LC filter).

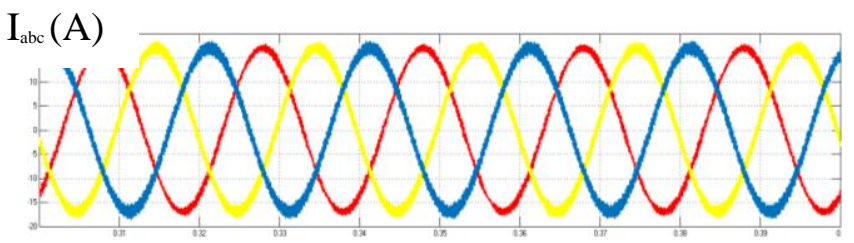

Fig. 9 Current waveform at supply side of EAF with LC Filter

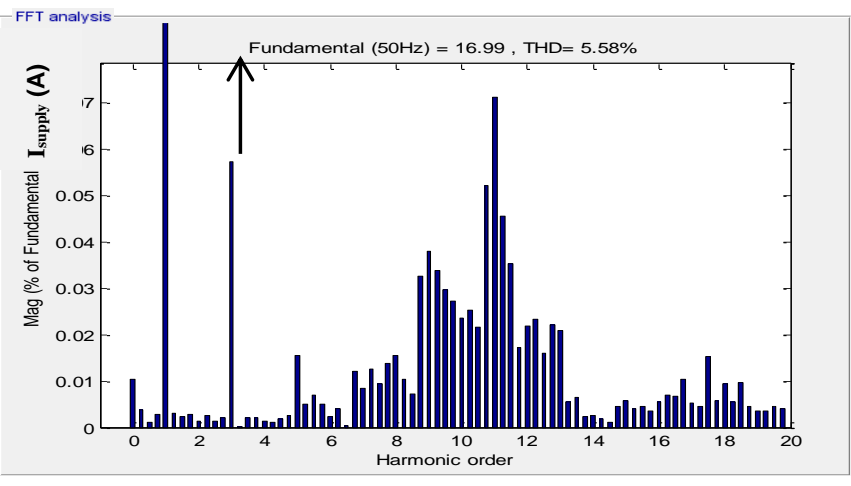

Fig. 10 FFT Analysis at supply side of EAF with LC filter
The analysis of THD for supply current with High pass, Double tuned and C-Type High Pass filters are as tabulated in Table II.

Hence, it is observed that C-Type High pass filters are suitable for EAF load for reduction of harmonics in supply current.

TABLE II COMPARISON OF THD FOR DIFFERENT PASSIVE FILTERS FOR EAF

\begin{tabular}{|l|l|l|}
\hline Filter Type & $\begin{array}{l}\text { Current } \\
\text { THD } \\
\text { (percentage) }\end{array}$ & \% Reduction \\
\hline Without filter & 35.64 & -- \\
\hline LC & 5.58 & 84.34 \\
\hline Double tuned & 2.96 & 91.69 \\
\hline High pass & 2.94 & 91.75 \\
\hline $\begin{array}{l}\text { C type high } \\
\text { pass }\end{array}$ & 2.78 & $\mathbf{9 2 . 1 9}$ \\
\hline
\end{tabular}

\section{HARMONIC REDUCTION ANALYSIS FOR EAF USING DSTATCOM}

\section{A. About DSTATCOM}

DSTATCOM is a compensating device used to regulate the alternating current and provide better power quality for the distribution network. The system scheme of a typical DSTATCOM is shown in Fig. 11.

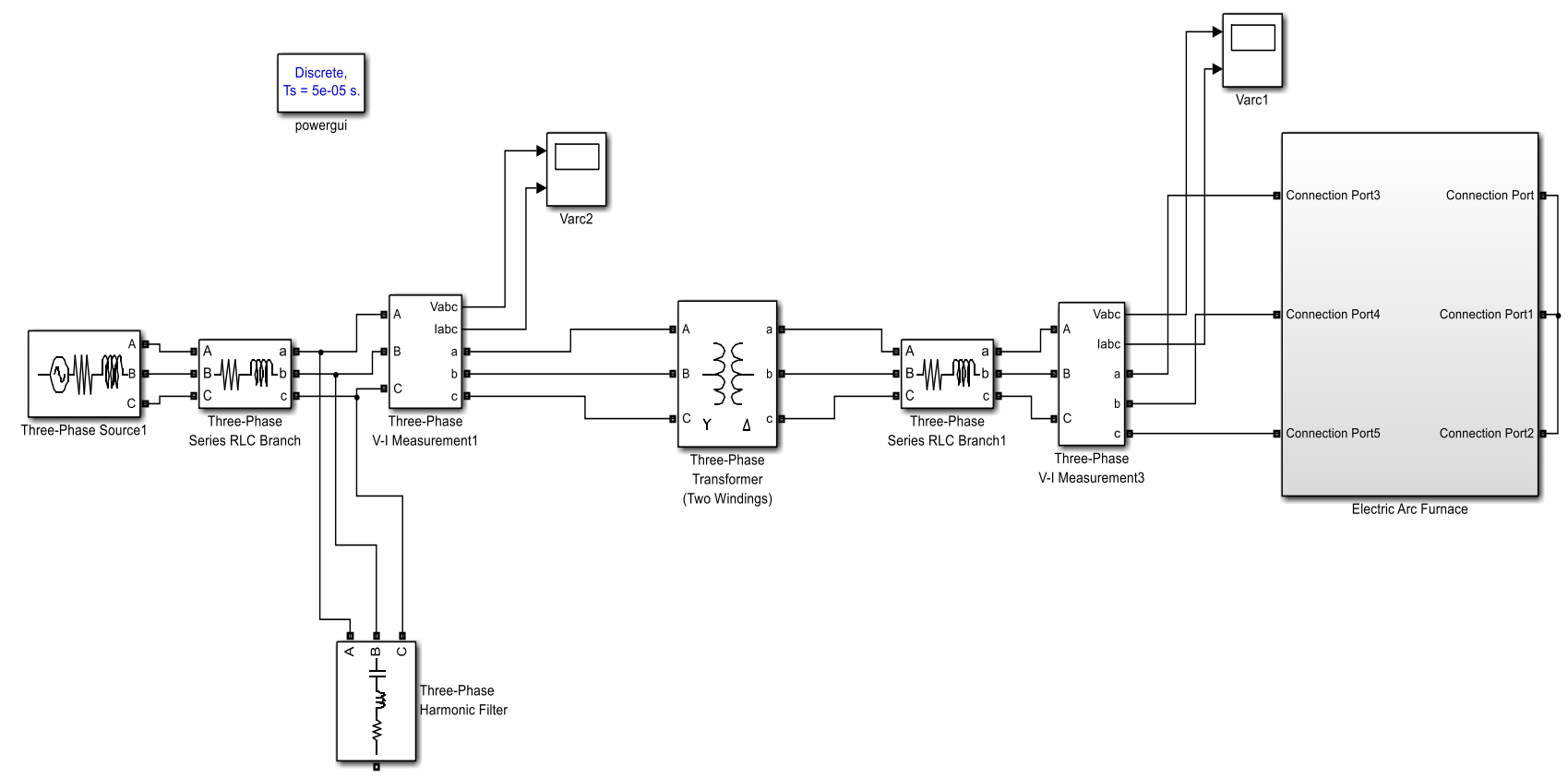

Fig. 8 Cassie-Mayr model of EAF with LC Filter 
The closed loop path consists of current and voltage magnitude sensing block, power quality analyzer and DSTATCOM. In this scheme of DSTATCOM, the shunt current $\mathrm{I}_{\mathrm{sh}}$ is injected so as to correct the reduction of voltage by regulating the voltage across the $\mathrm{Z}_{\mathrm{th}}$ - impedance of the system. The value of shunt injected current depends on the output voltage of the converter. The current $\mathrm{I}_{\mathrm{sh}}$ is given by $\mathrm{Eq}$ (2) and (3).

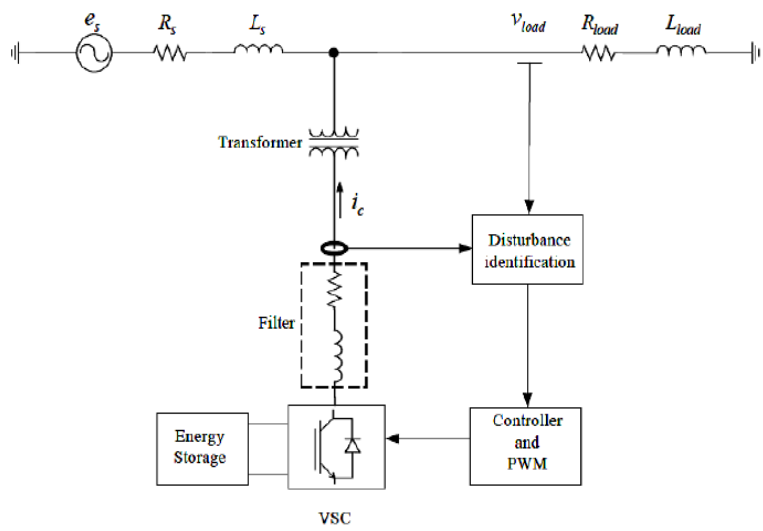

Fig. 11 System Scheme of DSTATCOM

$$
\begin{gathered}
I_{s h}=I_{L}-I_{s}=I_{L}-\left(V_{t h}-V_{L}\right) Z_{t h} \\
I_{s h} \angle \eta=I_{L} \angle \theta-V_{t h} Z_{t h} \angle \delta-\beta+V_{L} Z_{t h} \angle-\beta(3)
\end{gathered}
$$

The value of power injected $S_{\text {sh }}$ of the DSTATCOM is expressed in Eq (4).

$$
S_{S h}=V_{L} I_{S h}^{*}
$$

The impedance $\mathrm{Z}_{\text {th }}$ of the load bus indicates the effectiveness of the DSTATCOM. The shunt current $I_{s h}$ is aligned in quadrature with load voltage $\mathrm{V}_{\mathrm{L}}$ such that the magnitude of voltage to be corrected can be attained irrespective of active power injection into the system. If the required amount of shunt current is lower, then with the lower apparent power injection same voltage correction can be attained for the system.

When the impedance of source is connected in parallel with impedance of the load, the DSTATCOM works such that the voltage of load bus is equal to the product of injected current and impedance of the device. The supply current harmonics is eliminated and provides reactive power compensation. It also aids to decrease the fluctuations of voltage at the pcc. Usually VSC with a suitable PWM offers quick and consistent control.

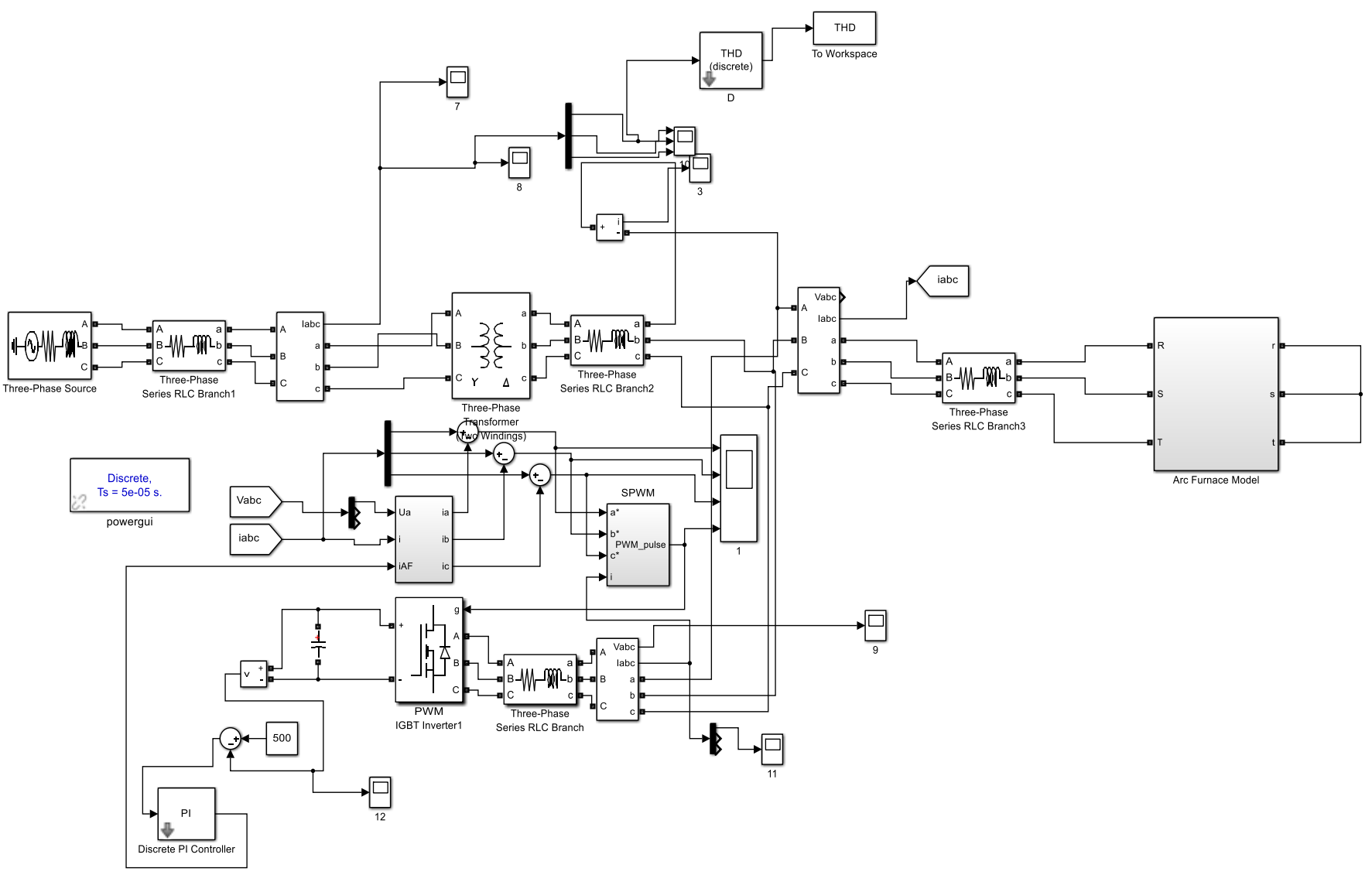

Fig. 12 Equivalent model for Induction furnace load with SPWM based DSTATCOM 


\section{B. MATLAB/SIMULINK Equivalent Model of EAF with DSTATCOM}

The system scheme of DSTATCOM shown in Fig. 11 is implemented for the proposed Cassie - Mayr model of EAF. In this work, the analysis of harmonic reduction for EAF with DSTATCOM is carried out for three types of controllers:

i. Sinusoidal Pulse Width Modulation (SPWM) control

ii. Hysteresis Current Controller (HCC) and

iii. Sliding Mode Controller (SMC)

The MATLAB/SIMULINK model of EAF with SPWM based DSTATCOM is as shown in Fig. 12. The supply current waveform of EAF with SPWM based DSTATCOM is as shown in Fig. 13. FFT Analysis at supply side of EAF is shown in Fig. 14. It is examined that the supply current THD decreases from $35.64 \%$ to $\mathbf{3 . 3 9 \%}$, with a net decrease of $90.48 \%$.

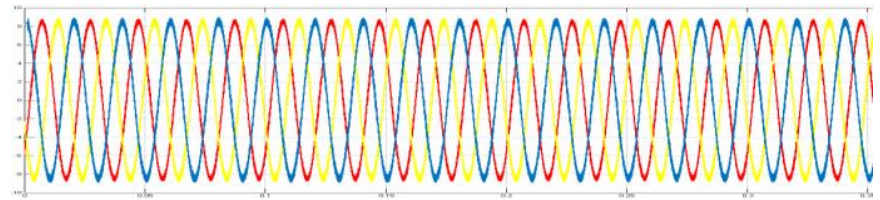

Fig. 13 Current waveform of EAF with SPWM based DSTATCOM

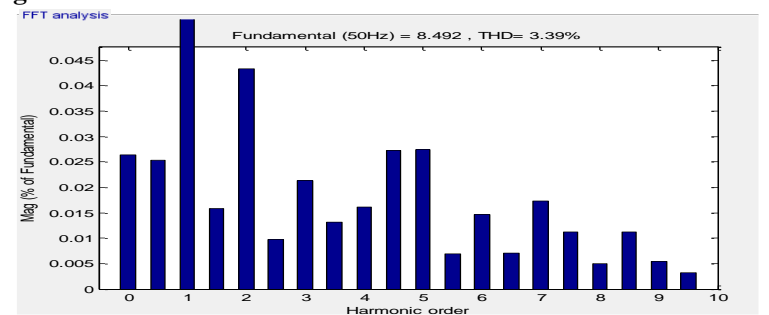

Fig. 14 FFT Analysis at supply side of EAF with SPWM based DSTATCOM

The MATLAB/SIMULINK model of EAF DSTATCOM with programmable input is shown in Fig. 15. The values that are measured at EAF steel plant are fed to the control circuit through program. Fig. 16 represents the current THD of $3.47 \%$ with SPWM based DSTATCOM at supply side of EAF.

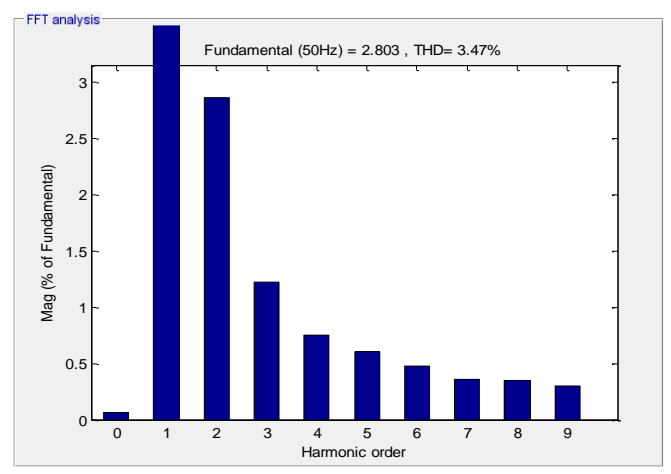

Fig.16 Current THD of EAF with SPWM based DSTATCOM

(with Programmable input)

The analysis of THD for supply current was also carried out with HCC and SMC controllers. Summary of the investigations conducted for SPWM, HCC and SMC control scheme of DSTATCOM for the equivalent model of EAF is as tabulated in Table III. The THD of current for SMC based DSTATCOM is $0.84 \%$ which is lowest compared to SPWM and HCC control schemes employed with a net decrease of $97.64 \%$.
Hence, it is observed that SMC based DSTATCOM provided better results for Electric arc furnace.

TABLE : COMPARISON OF THD FOR DIFFERENT EAF CONTROL SCHEMES OF DSTATCOM

\begin{tabular}{|l|l|l|l|}
\hline $\begin{array}{l}\text { Connection } \\
\text { scheme of } \\
\text { EAF }\end{array}$ & $\begin{array}{l}\text { Method of } \\
\text { control }\end{array}$ & $\begin{array}{l}\text { Current } \\
\text { THD } \\
\mathbf{( \% )}\end{array}$ & $\begin{array}{l}\text { Reduction } \\
\text { of THD (\%) }\end{array}$ \\
\hline \multirow{2}{*}{ Without Filters } & -- & 35.64 & -- \\
\hline $\begin{array}{l}\text { With } \\
\text { DSTATCOM } \\
\text { (Cassie-Mayr } \\
\text { Model) }\end{array}$ & SPWM & 3.39 & 90.48 \\
\cline { 2 - 4 } & HCC & 2.96 & 91.69 \\
\hline $\begin{array}{l}\text { With } \\
\text { DSTATCOM } \\
\text { (Cassie-Mayr } \\
\text { Model) } \\
\text { (with }\end{array}$ & SPWM & 0.84 & $\mathbf{9 7 . 6 4}$ \\
\cline { 2 - 4 } $\begin{array}{l}\text { Programmable } \\
\text { Input) }\end{array}$ & SMC & 3.47 & 90.26 \\
\cline { 2 - 4 } & & 2.04 & 94.97 \\
\hline
\end{tabular}

\section{CONCLUSION}

Electric arc furnace introduce appreciable amount of current harmonics into the distribution system, which affects the performance of other equipments connected in the network. The behavior of Electric arc furnace was investigated using MATLAB/SIMULINK to mitigate their current harmonics.

An equivalent model of Induction Furnace is developed and the Cassie -Mayr model of Electric arc furnace is proposed for the analysis of effective power quality improvement using passive filters and DSTATCOM.

The Simulation based passive filters such as LC, double tuned, high pass and C-type high pass filters were designed to reduce harmonics. The THD of current for C-Type High pass filter gave better harmonic reduction in supply current for the electric arc furnace model.

The effectiveness of DSTATCOM to reduce the current harmonics was investigated using MATLAB/SIMULINK for Electric arc furnace model. The DSTATCOM model executed with SPWM, HCC and SMC control scheme of DSTATCOM, where the SMC controller with programmable type input provided the better harmonic reduction than the other control schemes adapted for the proposed system. 


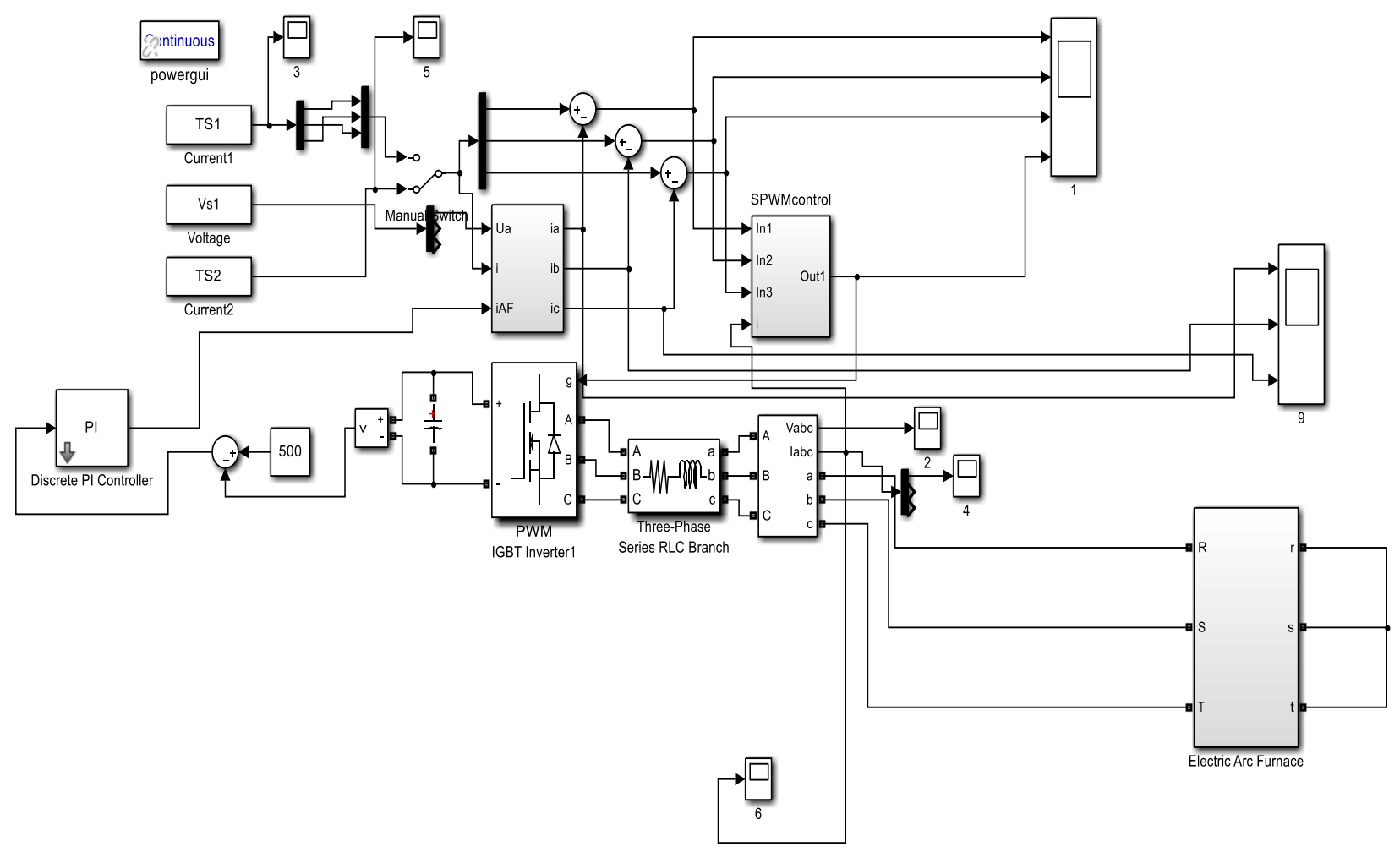

Fig.15 MATLAB/SIMULINK model of EAF with SPWM based DSTATCOM (with programmable input

\section{REFERENCES:}

1. Mohit Bajaj, Vinay Kumar Dwivedi, Ankit Kumar and Anurag Bansal, "Design and simulation of DSTATCOM for power quality enhancement in distribution networks under various fault condition", IJETAE, 2013

2. A. Tavakkoli M. Ehsan, S. M. T. Batahiee, M. Marzband, "A SIMULINK Study of Electric Arc Furnace Power Quality Improvement by Using STATCOM", 2008 IEEE International Conference on Industrial Technology.

3. IEEE Recommended Practice for Monitoring Electric Power Quality, IEEE Std 1159-1995.

4. Priyashree S, Harshithananda B, Vidya H.A, "Comparative Analysis of Hysteresis and Sliding Mode Controllers for Effective Reduction of Harmonics in Electric Arc Furnace Using APF", International Journal of Innovative Research in Computer and Communication Engineering (IJIRCCE), Vol. 5, Issue 4, ISSN(Online): 2320-9801, ISSN (Print): 2320-9798, APRIL 2017.

5. Minarti Mane, Mini K. Namboothiripad, Fr. C. Rodrigues Institute of Technology , "Current Harmonics reduction Using Sliding Mode Control Based Shunt Active Power Filter", 10th International Conference on Intelligent Systems and Control (ISCO), 7-8 Jan 2016, IEEE Xplore.

\section{AUTHORS PROFILE}

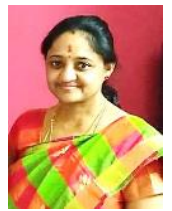

Priyashree $\mathrm{S}$ received her B.E. degree in Electrical and Electronics Engineering and M.E. in Power \& Energy Systems from Bangalore University, Bangalore in 2001 and 2004 respectively. She has secured First Rank in M.E from Bangalore University. She has worked as Lecturer (2004 2008), Assistant Professor (2008 - 2012) and Associate Professor (2012 to till date) in Department of Electrical \& Electronics Engineering, BNM institute of Technology, Bengaluru. She has completed her Ph.D (Electrical Sciences) in 2019, under Visvesvaraya Technological University, Belagavi, under the guidance of Dr. Vidya H A, Professor, Department of Electrical \& Electronics Engineering, Global Academy of Technology, Bengaluru . Her research interests are in the areas of Power Quality and Signal processing.

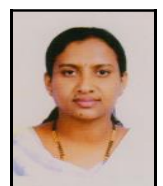

Vidya .H.A received her B.E. degree in Electrical and Electronics Engineering from NIE, Mysore University, Mysore and the M.Tech. in Computer Application in Industrial Drives from NIE, Visvesvaraya Technological University, Belgaum in 1996 and 2001 respectively. She has secured First rank in M.Tech from Visvesvaraya Technological University. She has completed her Ph.D in electrical sciences in 2008 from M.S. Ramaiah R\&D centre under VTU. She has worked as a Lecturer in KVG College of Engineering, Sullia from 1997 to 2003 and she has handled various positions at BNMIT, Bangalore from 2003 to 2015. Currently she is working as a Professor, Department of Electrical \& Electronics Engineering, Global Academy of technology, Bengaluru. Her research interests are in the areas of Signal Processing, High Voltage and Power Quality. 